\title{
LOCAL DEVELOPMENT INITIATIVES AS PROMOTERS OF SOCIAL INNOVATION: EVIDENCE FROM TWO EUROPEAN RURAL REGIONS
}

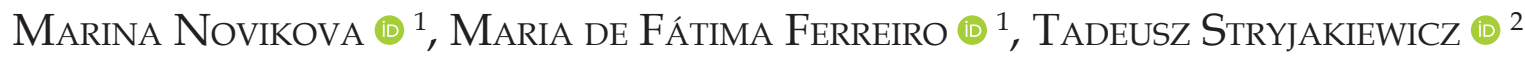 \\ 'DINÂMIA'CET-IUL - Centre for Socioeconomic and Territorial Studies, University Institute of Lisbon, Lisbon, \\ Portugal \\ ${ }^{2}$ Institute of Socio-Economic Geography and Spatial Management, Adam Mickiewicz University, Poznań,
} Poland

Manuscript received: January 15, 2020

Revised version: April 5, 2020

\begin{abstract}
Novikova M., de Fátima Ferreiro M., Stryjakiewicz T., 2020. Local development initiatives as promoters of social innovation: Evidence from two European rural regions. Quaestiones Geographicae 39(2), Bogucki Wydawnictwo Naukowe, Poznań, pp. 43-53. 1 fig.
\end{abstract}

ABSTRACT: Social innovation entered the academic discourse several decades ago and has since been seen as a way of tackling existing problems in various contexts. Although an extensive body of research has been conducted into the role of social innovation in urban context, there is still a gap when it comes to studying the role of social innovation in the development of rural areas. In this paper, an attempt is made to look at the role of Local Action Groups (LAGs) and Local Development Associations (LDAs) as promoters of social innovation in rural areas in Austria and Portugal, aiming to understand the role of such organisations and the challenges faced by the latter in promoting social innovation.

KEYWORDS: social innovation, local action groups, local development associations, rural regions, Austria, Portugal

Corresponding author: Marina Novikova, ISCTE-Instituto Universitario de Lisboa, Avenida das Forças Armadas,

1649-026 Lisbon; e-mail: Marina_Novikova@iscte-iul.pt

\section{Introduction}

According to Eurostat, more than half (as for 2012) of the land area in the European Union is within regions classified as being predominantly rural $^{1}$ (Eurostat 2016). Such areas are often characterised by issues of depopulation (Margaras

According to the European Commission (2014), rural is considered to be an area where more than $50 \%$ of the population live in rural grid cells. Eurostat gives an explanation in which NUTS III regions are classified as 'predominantly rural' if the share of the population living in rural areas is higher than $50 \%$.
2019), weak economic performance (Dax, Fisher 2018) and large physical distances to end markets (Tregear, Cooper 2016). In order to overcome these challenges, rural development policy has sought out novel solutions through social innovation (SI). However, despite there being various approaches to SI in territorial development, few have addressed the phenomenon in a rural context, with the notable exception of Neumeier (2012, 2017), Bock (2016) and Bosworth et al. (2016). There is still a lack of knowledge on how SI emerges in rural areas and how it might contribute to an area's development. In addition, the 
drivers and promoters of SI in rural regions remain rather unexplored despite attempts to analyse the role of actor networks (Neumeier 2012), local communities (Di Iacovo et al. 2014) and social enterprises (Richter 2019) in the process of SI promotion.

The importance of SI in rural development comes from a paradigm shift towards a more 'qualitative' development of regions, focusing on dimensions such as the population's wellbeing, network building, local participation and capacity building. Indeed, the literature (e.g. Dax, Fisher 2018) suggests that future approaches to regional development will have to go beyond the economic growth paradigm and will have to focus more on issues such as local participation and SI.

This article examines LAGs and LDAs role in promoting SI in rural regions and how their work responds to their respective region's issues by using the cases LAGs and LDAs in the Mühlviertel (Austria) and Baixo Alentejo (Portugal) NUTS III regions. The results of the study show that by addressing the issues of empowerment, capacity building, inclusion and network building, LAGs and LDAs contribute to the overall development of a given region. However, irrespective of this success, such organisations face various challenges comprised of bureaucratic burden, difficulties with finances and the need to work towards changing community perceptions of both their work and the region.

The article is structured as follows. First, theoretical underpinnings regarding SI are presented. Second, the role of SI in regional development, namely in the (neo)endogenous development of rural regions, is discussed. Following that, the methodology alongside the cases under study is presented. Finally, the role of LAGs and LDAs as promoters of SI is analysed along with the challenges and opportunities of such promotion.

\section{Social innovation as a concept of complementary meanings}

Despite the steady growth of academic interest in the field of SI (Moulaert 2016; Phillips et al. 2015), its role in rural development still remains underexplored with most research concerning urban SI (e.g. Moulaert 2010; Angelidou, Psaltoglou
2017). Despite this, what research there has been into the importance of, and drivers behind, SI for rural development (Dargan, Shucksmith 2008; Neumeier 2012, 2017; Bock 2016), the field has been gaining momentum.

In general, 'innovation appears to be a novelty in a given setting based on the recombination of existing elements, the transfer of ideas or solutions to or from other contexts, or inventions' (Richter 2019: 179, citing Schumpeter, 1983 [1911]). SI, in turn, relates to 'changes of attitude, behaviour and/or perception that result in new forms of collaborative action', which, then, improve the lives of those involved (Neumeier 2012: 55). Thus, SI is not only about meeting unmet needs, it is also concerned with the way in which this is done (e.g. through enhancing the capacity of actors, building networks and empowering disadvantaged groups). It involves new forms of organisation at both an institutional and personal level, which are developed at the local level and result in social changes beneficial to the communities involved (Moulaert et al. 2005). According to Bock (2012), SI as a concept originated from the 'debate and critique on traditional innovation theory with its focus on material and technological inventions, scientific knowledge and the economic rationale of innovation' (Bock 2012: 57). Whilst looking into various conceptualisations and definitions of SI, 'social' is being placed to be a 'core element of innovation' (Bock 2012: 59).

The extant debate on the nature of SI indicates some concern in the literature about the term being conceptually 'fuzzy' and consequently lacking a critical edge (e.g. Pol, Ville 2009; Bock 2012; Neumeier 2012). According to Marques et al. (2018), there is 'a need for a clearer distinction between SI as a research concept that is used to study specific phenomena, as a normative concept that serves as a guide for action, and as a concept in practice, where it is used to describe a wide range of activities from a variety of public, private and third sector actors' (Marques et al. 2018: 497).

According to Neumeier (2012), the theoretical concept of SI is built on the following key aspects. First, that SI is grounded in the alliances of different actors. This means that SI occurs through the aligned interests of a group of actors if only a certain critical mass of such actors decides to enrol into the actor network (Neumeier 2012: 54). Thus, 
for the process of developing SI, a network of actors with aligned interests is crucial. Second, he argued that the development of SI (as is the case for other types of innovation) is always triggered by an initial impetus whether that impetus is external or internal to the group of actors involved in the process of SI. Third, SI builds on the aspect of relative novelty. The relative novelty of a SI, therefore, is the novelty in the subjective perception of the individuals involved (Neumeier 2012: 55). In this sense, SI might also not be new per se but new to the context in which it is implemented. Fourth, SI has as main focus changes of attitudes, behaviours or perceptions (of a group of people aligned in the network). Fifth, the practical implementation of SI is connected with the fact that a particular SI is seen by the people involved as a superior solution (for existing challenges or unmet needs) compared to those that currently exist. Finally, according to Neumeier, $\mathrm{SI}$ is non-material that implies that the material outcomes of SI are a supplementary result.

Building on the (main) characteristics of SI described above, the next section discusses the role of SI and its potential contribution to the (neo-endogenous) development of rural areas.

\section{Social innovation and the neo- endogenous development in rural regions}

The traditional image of a rural region is of an area that is lagging behind due to the limited capacity of actors and groups to participate in economic activities (Bock 2016). Some literature suggests that rural areas are perceived as lacking innovation in comparison to their urban counterparts (e.g. Shucksmith et al. 2009). However, this view is contested by other scholars, who identify rural regions as those that, despite structural disadvantages such as poor resource accessibility and detachment from markets and networks (Bock 2016), develop creative solutions for existing challenges and have the drive needed for the development and implementation of innovative projects. Thus, the development of rural areas requires an approach that goes beyond just a technological and economic focus and places more emphasis on dimensions such as the improvement of the quality of life of the rural population.
Technological innovations alone cannot solve the challenges of ageing populations, low population density exacerbated by brain drain of young people and weakened economic activity. Such challenges require solutions that would not just contribute to solving the challenges and future development of the regions but would do so through involving local populations in the design of such solutions. Such an approach could be described as neo-endogenous.

As suggested by Neumeier (2012), a neo-endogenous development framework, while still recognising the need for external participation in the development process (and the usual presence of an external impetus as well), places greater emphasis on utilising local resources and enhancing local participation in order to boost the development of a given rural region. In his article, Ray (2006) stated that the neo-endogenous approach in rural development 'emphasises the principle and process of "local participation" in the design and implementation of action' (Ray 2006: 278) through its two primary characteristics. First, the development activities (including economic development) are 'reoriented to maximise the retention of benefits within the local territory by valorising and exploiting local resources', both physical and human (Ray 2006: 278). Second, the main focus of the development is placed on needs and capacities of local people (Ray 2006).

The role of SI for the development of rural areas has been discussed in the literature from different perspectives. As previously said, SI can support the sustainable rural development through building on neo-endogenous strategies (Neumeier 2012). Through enhancing more efficient collaboration amongst the (local) actors (Dobele et al. 2015), SI helps to mobilise local resources to satisfy local public needs and, at the same time, creates economic value (GarcíaLlorente et al. 2016) as well as contributes to the creation of networks amongst local actors (Neumeier 2012; Gobattoni et al. 2015). SI, considered an innovation of and for society, includes rethinking social and spatial solidarity within and beyond rural regions (Bock 2016). To this end, SI encourages local linkages and collective learning cultures (Navarro et al. 2018). In addition, and, perhaps most importantly, by bringing change to rural regions, SI challenges existing institutional contexts (Hulgard, Ferreira 2019). 
Having identified the existing gap in the research field of (rural) SI, the following section presents the methodology used in order to study the role and the contribution of local action groups (LAGs) and local development associations (LDAs) in promoting SI in rural regions.

\section{Research design and methodology}

This article presents the results of an explorative study based on semi-structured interviews conducted between October 2018 and May 2019 in two NUTS III regions Mühlviertel, Austria, and Baixo Alentejo, Portugal. Expert interviews were conducted to get an initial insight into the challenges that rural regions face, the (novel) solutions that have been provided for those challenges and the impacts of such solutions. To ensure data, several groups of experts were identified during the exploratory stage of the research. The first stage of exploring the field was performed via desk research wherein experts were identified, followed by the initial recruiting of experts. The groups contained representatives of development actors from the local, regional and national levels. The sampling procedure was based on the snowballing technique, where key experts identified through desk research were asked to provide potential references to key actors in the field of regional development, rural development and so on.

As regional and local development happen at different levels and in different organisations, the experts invited for interviews represented local development associations, local action groups (in the framework of LEADER; an acronym in French for Liaison entre actions de développement de l'économie rurale ${ }^{2}$ ), social enterprises, local administration, intermunicipal community, regional development agencies, business association, regional management agencies, network of LEADER regions, SI incubator and regional development commission, as well as federation of

The LEADER programme is a European Union initiative to support rural development projects initiated at the local level in order to revitalise rural areas. Its aim is to involve local actors in rural areas in the development of their own regions by forming Local Actions Groups (LAGs) and designing and implementing strategies.
LDAs. Twenty-eight interviews were conducted during the data collection stage: 14 interviews for the Austrian case and 14 interviews for the Portuguese case. In order to ensure triangulation of data, additional sources of information, such as local development strategies from two cases were analysed alongside other sources such as Lokale Agenda 21 and material on LAGs and LDAs web pages. On the basis of the data collected, and their subsequent analysis, the following section provides insight into the contribution of LAGs and LDAs into the promotion of SI (alongside some examples of past projects), contextual factors that affect such promotion alongside the challenges and obstacles faced by LAGs and LDAs.

\section{Study areas}

Baixo Alentejo (Portugal) and Mühlviertel (Austria) are presented as cases to investigate the role of LAGs and LDAs in promoting SI in rural areas (Fig. 1). First, two regions were chosen as study areas based on their different backgrounds in regional development (where Austria is considered amongst the pioneering countries). Second, both regions, despite falling under the category of predominantly rural, are not experiencing challenges such as low economic activity, rural exodus and ageing of population to the same extent. Third, two regions are quite different in the population and territory. Despite all the differences, the activities promoting SI are undertaken in both cases, which make an interesting ground for finding the commonalities and divergences in the ways of promoting SI.

Baixo Alentejo, part of the larger Alentejo region (NUTS II), covers an area of $8,544.6 \mathrm{~km}^{2}$ (10.8\% of the national territory). The region is bordered to the north by the District of Évora, to the east by Spain and to the south by the District of Faro. Baixo Alentejo consists of 13 municipalities (Municípios) and 83 parishes (Freguesias). The total population of Baixo Alentejo in 2018 was reported as 117,868 inhabitants (INE 2019). Compared to the national as well as regional population densities (NUTS II), Baixo Alentejo represents one of the most sparsely populated regions in Portugal with a decrease in population density from 14.5 inhabitants $/ \mathrm{km}^{2}$ in 2013 to 14.1 inhabitants $/ \mathrm{km}^{2}$ in 2017 (Eurostat 2019). Over the 

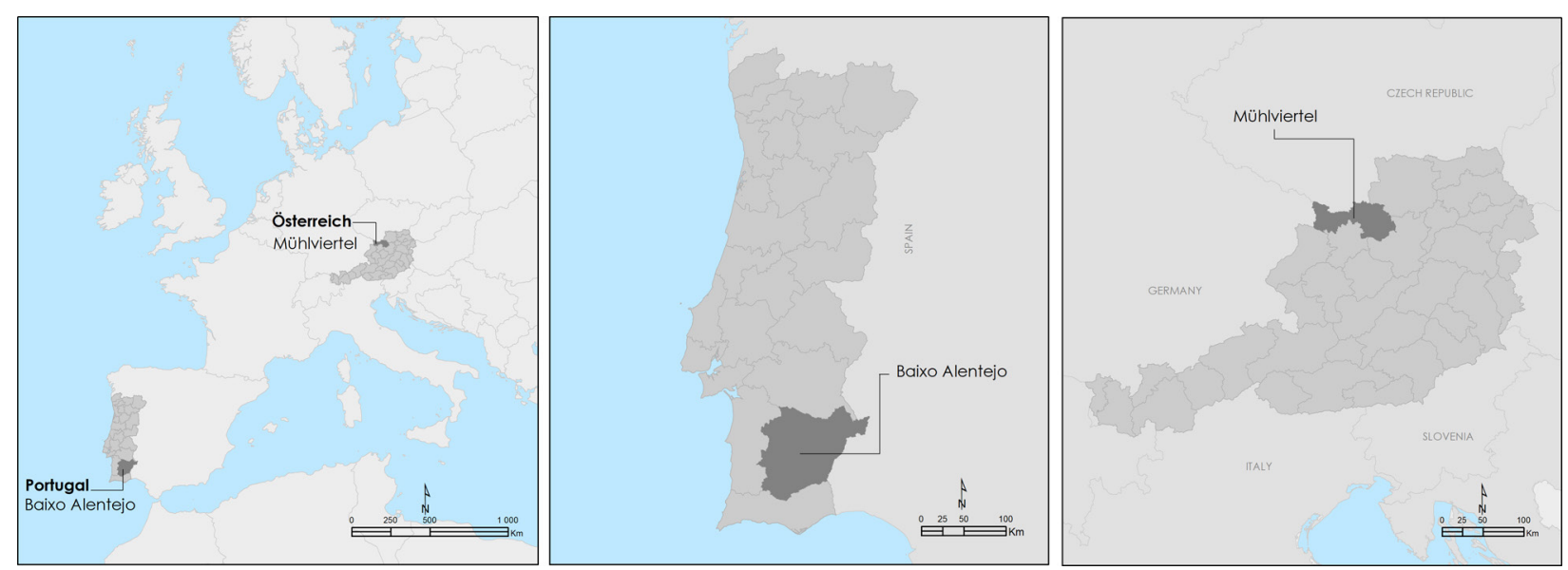

Fig. 1. Map with the location of two regions under study.

Source: own elaboration based on Eurostat data.

past decades, the region has undergone an average negative population growth because of rural exodus, which especially concerns younger population and ageing of the population (Margaras 2019). Economic sectors related to production of cork, wine, olive oil and dairy products occupy a prominent space in the economic activities of the region. However, the tertiary sector has, in the recent years, taken a prominent position in the regional economy because of the development of the information and communication technologies (ICT) and tourism (e.g. sustainable and ecotourism). Being a low population density region with relatively low diversification of economic activity, Baixo Alentejo is an area where LAGs and LDAs strive to create a support system for revitalising the region through triggering the positive development of it through the ideas of SI. As derived from the interviews, LAGs and LDAs identify the areas of social care for elderly people, youth integration, economic diversification alongside with the development and promotion of alternative economic models and its strengthening as main objectives of their work in rural development.

Mühlviertel is part of the Upper Austria region (NUTS II), covering an area of 2,660.17 $\mathrm{km}^{2}$. The region borders on Bavaria and Bohemia to the north and Lower Austria to the south and east. Mühlviertel consists of 4 political districts (politische Bezirke) and 120 municipalities (Gemeinde). For a 5-year period, the region has experienced an increase in the population density from 77.7 inhabitants $/ \mathrm{km}^{2}$ in 2013 to 79.2 inhabitants/ $\mathrm{km}^{2}$ in 2017 (Eurostat 2019). Total population of
Mühlviertel in 2018 was 208,483 (Eurostat 2019), which indicates the increase in the total number of inhabitants in the region since 2013. When it comes to the economic sectors of the region, because of the relatively large distances to metropolitan areas and the low population density, agriculture has an important economic and social role in the region. As in Portuguese case, members of LAGs and LDAs operating in Mühlviertel have identified the youth engagement, female entrepreneurship alongside economic development and agriculture (with a strong focus on ecological farming) as their main fields of intervention that require new and creative solutions.

According to Eurostat (2016), both regions under study are predominantly rural and peripheral ${ }^{3}$ regions but they are not facing the same challenges in terms of population and economic development. Despite having different backgrounds in economic and demographic development, two regions represent an interesting arena for socially innovative projects of LAGs and LDAs. Analysing the work of LAGs and LDAs operating in two quite different rural contexts, the next section analyses the ways in which those organisations approach (rural) challenges, such as low population density, ageing of the population as well as strong connection of economic activity to agriculture, and how they contribute to solving them through novel solutions.

In this article, the notion of 'peripheral' is applied to the region based on the geographic location, for example, the region bordering other countries. Both regions, therefore, fall under the category of peripheral. 


\section{Ways of promoting social innovation used by LAGs and LDAs in Baixo Alentejo and Mühlviertel}

In both cases under study, there is a high awareness of SI amongst the members of LAGs and LDAs. This may be explained by the entrance of SI into the policy discourse some time ago, leading to it being seen by interviewees as a tool that has the ability to help the development of their respective areas. Implicitly, such actors identify their work as SI based on the dimensions of an idea or a project being novel for the specific locality, the attempt to meet needs whilst involving the local community in co-creation as well as practicing a bottom-up approach to project development. As pointed out by an interviewee in the Austrian case,

social innovation means that people allow new ways. Any positive social innovation should provide positive input, positive ground for providing something new. For social innovation you also have to look to other regions, to take the practices from other regions. If other good projects run there it could also run here (LAG manager, Mühlviertel, October 2018).

This understanding of SI and its importance for regional development was echoed by interviewees in the Portuguese case, where SI is seen as a tool for more sustainable, collaborative and goal-oriented actions:

[Social innovation is] putting people together, working together in a participatory way to solve their own problems, this is the idea I have for that (a member of the Portuguese Federation of Local Development Associations, Lisbon, April 2019).

Despite the promotion of SI having a more implicit character in two case studies, LAGs and LDAs take on various ways to promote novel solutions for the regions they work in.

\section{Being an intermediary}

According to Richter (2019), it is assumed that rural social enterprises are more capable of fostering SI in rural regions if they are socially embedded in the region and if they systematically connect 'remote rural communities with groups, organisations, and networks in other places, fields, and spatial scales' (Richter 2019: 185). Despite the fact that LAGs and LDAs are not necessarily social enterprises, the above still holds true for such organisations. By serving as an intermediary (an embedded intermediary, in Richter's terms), LAGs and LDAs serve as a bridge between members of a local community, between local communities and regional authorities (such as Regional Directory of Alentejo), between actors on local level and national networks and groups and between local and EU levels through the direct communication in case of LAGs. In addition, because the research concerns rural regions on the periphery of Austria and Portugal, those organisations serve as an intermediary in cross border cooperation between various regions. By connecting a local community with external actors (and exogenous resources), LAGs and LDAs promote cooperation, know-how exchange and inclusion of local actors into the supra-regional networks beyond their respective regions, which supports the neo-endogenous approach to the rural development where actors are connected to wider contexts (Neumeier 2012; Bock 2016). Facilitating access to the (financial) resources is another important part of such organisations' work, especially in rural areas where organisations and individuals usually find themselves in a situation of a limited access to the resource pool. By facilitating access to various sources of funding, the most important of which being LEADER and European Regional Development Fund (ERDF), LAGs and LDAs provide local communities with more opportunities for financial support available for both existing and emerging initiatives.

\section{Promoting an integrated approach to rural development}

In both cases, LAGs and LDAs strive for integrated development, meaning, the projects implemented by organisations cover various fields within one project rather than targeting only one domain, for example, promoting tourism through the use of natural assets and local knowledge. In most of the projects, such organisations strive to promote holistic development by interventions covering diverse groups of people (e.g. elderly, young and female) simultaneously while also 
not limiting their projects to specific domains of (purely) economic or social development. In both regions, the integrated sustainable development through projects concentrating on different combinations of interventions was said to be one of the main objectives. Such an integrated approach is especially supported by LAGs and LDAs because the public sector does not always work in an integrated way. As a member of a Portuguese LDA pointed out,

[Municipalities] can see what is happening, but they lack an integrated approach. Even in small municipalities, they have those different departments, and there is no common strategy, each of the departments works only within a specific subject. And this is happening all over. The local development associations have a much more integrated approach on the territory than the municipalities themselves (a member of an LDA, Baixo Alentejo, March 2019).

One of the initiatives promoting an integrated approach is the EPAM (Empreender na Fileira das PAM em Portugal; translated as Business development in the aromatic and medicinal plant sector in Portugal) project. It has been led by ADCMoura since 2011 and driven by the National Rural Network Program. The project embodies a consolidated methodology and set of tools to support the development of the aromatic and medicinal plants sector in Portugal. It acts at the level of network animation, research and provision of information, training and serving as a strategic and innovative platform. One of the cornerstones of the EPAM process is fostering collaborative solutions for business and industry development amongst producers and between producers and other industry agents such as researchers as well as public bodies and companies.

A similar approach is taken in Mühlviertel where LAGs see integrated rural development as one of the main strategic objectives of their work. Operating in the region, the Bioregion Mühlviertel association that includes stakeholders with all six LAGs of the Mühlviertel being a part of it, is a network that encompasses organic direct marketing companies, gastronomy and the hotel industry, schools, organic farming businesses and commercial organic food processors. Through strengthening cooperation and participation and creating closed value-added cycles in the organic sector, BioRegion Mühlviertel aims to support and ensure sustainable regional development.

\section{Bringing capacity to the region}

In both cases, capacity building among local populations is named as one of the main goals of LAGs and LDAs. By organising meet-ups, workshops and one-on-one consulting to those wishing to open their own enterprises, such organisations build local/regional capacity. Throughout the interviews, it was noted that one of the main objectives is the establishment of a system (a support infrastructure) wherein the local community would acquire the entrepreneurial capacity necessary for their own autonomy in the future life of their projects:

So, this is more or less what we do, in that case it was with social care for elderly people, but this place to other sectors and other ideas. And this is how we started working with the aromatic and medicinal plant sector. The idea is to help people develop their own capacity and empower them in order for them to be able to develop the sector by themselves (a member of an LDA, Baixo Alentejo, March 2019).

Another important aspect of their work is to bring external knowledge and know-how to the regions from partners in other regions and countries, exchanging experiences and practices in frameworks such as LEADER and INTERREG (European Territorial Cooperation). By taking part in projects as partners and exchanging expertise with external experts, LAGs and LDAs bring necessary (and sometimes lacking) knowledge back to the region and share it through workshops, classes, lectures and so on targeting both internal stakeholders and local communities.

\section{Promoting shift from problem oriented to opportunity-driven development and social innovation}

Rural development has experienced a shift towards available local assets that should be perceived as an opportunity and a valuable feature rather than an obstacle (Dax, Fisher 2018). Despite the fact that most literature refers to SI as a new way of solving problems or meeting needs, 
opportunity- and asset-driven SI are rarely discussed in lieu of problem solving. The organisations in both cases under study took an approach towards the challenges faced by regions as opportunities, in an attempt to change both the way of work and the perception of local populations towards such work and the situation in their respective regions.

Another one is that we should look for the things that we normally see as a problem and change it and see it as an opportunity. And we are doing it, there are some examples... For instance, the low density of people, of houses, of companies, we have space in the region with no light pollution, dark sky. It's an example of how we can use low density as an opportunity to promote other activity (a member of the Alentejo Regional Development Agency, Alentejo, May 2019).

The importance of promoting opportunity-driven, rather than solely problem solving, SI stems from the fact that opportunity-driven SI can potentially provide more transformative outcomes (Bosworth et al. 2016) despite the fact that the problem-oriented actions can provide the best available solution at a given time.

\section{Utilising (natural) assets of the region}

New economic sectors are now developing in rural areas, such as the expanding sector of rural tourism and other activities linked to their natural and cultural assets (European Commission 2008). This is confirmed by the words of another interviewee:

The environmental excellence that we have is the result of not having so many companies, so many people. So now it's a very good thing that we have that we should keep but explore at the same time, so we have to look for that (a member of the Alentejo Regional Development Agency, Alentejo, May 2019).

In both case studies, therefore, rural tourism is seen as a promising sector that both helps regions to attract tourists while staying true to a sustainable approach to the development as well as making use of the regional resources and assets on offer. The attractiveness of available natural assets and resources is used by LAGs and LDAs not only to attract tourists to the region but also to attract more young people to rural areas by showcasing the (high) quality of life and availability of support infrastructure to realise their own initiative.

On the basis of the different ways in which LAGs and LDAs promote SI in rural areas, some conclusions can be drawn. The promotion of SI is performed through the complementary functions, which such organisations use in their work. The important objective of their work is promoting an integrated approach to the development of their respective rural regions. LAGs and LDAs work is to foster SI and, at the same time, the ways in which those organisations do this can also be considered a type of SI because it promotes cooperation, targets the change in people's perceptions (of existing challenges and available resources and assets), creates and strengthens networks and attempts to provide novel, opportunity-driven solutions.

\section{Opportunities and challenges in promoting social innovation}

The promotion of SI in both regions can be described as implicit rather than explicit: by realising projects aiming at regional and local development, such organisations do not necessarily strive to promote SI as an analytical concept but so as to provide new solutions and ideas for dealing with the challenges that territories and communities face. However, by following an integrated approach striving to meet unmet needs while including the local population in the process of co-designing the projects and creating networks among the locals, LAGs and LDAs can be assumed to be promoters of SI by both placing the emphasis on the process and the outcome dimensions of SI.

The importance of cross-border constellations of actors in the process of the development and promotion of SI projects is supported in the academic discourse (e.g. Noack, Federwisch 2019). For the Austrian case, the results show that, during the early 1990s, some municipalities in the Mühlviertel region came together to develop a set of measures to promote regional collaboration. The working group was set up in order to develop a strategy for a collective 'regional' acting in order to overcome the challenges that existed 
in the region at the time such as weakened economic performance and decreasing population, especially the outflow of young skilled workers. In the process of developing new solutions for overcoming the challenges described above, the interviewees pointed out the importance of a collaborative approach in finding a new sustainable approach to regional development. Such development, however, is not seen as a development of separate municipalities but rather as a development of an overall Mühlviertel region:

At this time, there were eight municipalities and they thought it would be much more than a broader part and it was: what is with the social life and everything, so they decided to design a process to make the regional development more than only agricultural development, more than only touristic development. It is still important but it is not the only part. So we designed a process together (a member of a cooperative operating in the region, Mühlviertel, November 2018).

In the Portuguese case study, such collaborative approaches are rather contested despite the fact that there is collaboration amongst LAGs and LDAs. In contrast to the Austrian case, members of LAGs and LDAs in Baixo Alentejo pointed out the existing challenges in promoting a collaborative spirit. As one of the reasons for this, an interviewee suggested the overall competitive spirit of enterprises and companies in the region:

[enterprises] see themselves as concurrent, not as partners. Everyone wants to be a leader, this area is mine, so I'm afraid to share it with others. But at the same time they have to do it because we are very small. We cannot grow, we need to share more, work more together (a member of the Alentejo Regional Development Agency, Alentejo, May 2019).

The background in traditional agriculture was also said to hamper the possibilities (and willingness) of the local population to either start their own initiatives or get involved in entrepreneurial projects supported through the work of LAGs and LDAs in Baixo Alentejo. As stated by an interviewee,

for years for the regular person was to work for someone and not to think about creating his own job, starting his own initiative. So this remains the mentality that someone has to give me a job. So when we say that today we still have a lack of qualification, it is not only about the professional qualification, but especially some competences that people don't have in terms of entrepreneurial attitude (a LAG manager, Baixo Alentejo, May 2019).

Promoting SI is related to several other challenges faced by LDAs and LGAs. First, the results showed that there is a low degree of institutionalisation of SI in both cases under study. Local development strategies in both cases (Lokale Entwicklungstrategie in Austria and Estratégias de Desenvolvimento Local in Portugal) do not refer to SI explicitly. The discourse regarding the development in local strategies is rather centred around the importance of implementing and supporting innovation in various fields of intervention; however, it does not put SI as a distinct category of action.

Amongst other factors disabling the promotion of SI are (relatively) high levels of bureaucratic burden in organisations, lack of time in order to work in the field (described by interviewees as on the ground), presence of some hostility among locals towards projects, ongoing presence of centralised decision-making on local development, a lack of critical mass among a local population, the presence of parochial thinking, the necessity for the success of projects that leaves no room for mistakes together with the lack of cooperative culture amongst actors. As stated by one of the experts,

On the other hand, the way that the programs have been designed in each cycle constrained a little bit all this freedom and this innovative capacity that LAGs had in the beginning. [...] but they don't have time now because if they want to not be left behind on levels of engagement and funds and expenses they have spent too much time on dealing with the procedures, bureaucracy and less time to do, which I think is the really added value working together with people, what we call this territorial dimension (a member of the Portuguese Federation of Local Development Associations, Lisbon, April 2019).

In both cases, the work performed by LAGs and LDAs is project-based, which means that (1) the organisations face tight deadlines in releasing 
and finishing the projects; (2) there is substantial pressure concerning the success rate of the projects, namely, there is a need for a project to be successful; (3) not all the outcomes and impacts of the projects implemented live on after the financial support ends which raises the question of sustainability of actions and sustainability of innovation. According to Dax et al. 2016 (citing Strahl, Dax 2010), LAGs 'feel constrained by the growing set of regulations while also losing their ability to make use of locally specific rural assets through an innovative approach' (Strahl, Dax 2010: 38). This has been confirmed throughout the interviews in which, in both cases, the experts pointed out the (still) growing pressure from centralised decision-making procedures combined with the enormous bureaucratic burden put on them.

\section{Discussion and conclusion}

Most interviewees emphasise that LAGs and LDAs play an important role in promoting the development of rural regions while implementing changes and cooperating in a way that can be considered socially innovative (new, hybrid partnerships in order to tackle challenges; promoting integrated area development rather than the development of specific sectors, e.g. agriculture; supporting bottom-up actions). The awareness regarding SI initiatives is high; however, in both cases, organisations tend not to immediately describe their work as SI. Yet, people involved in LAGs and LDAs both in the Portuguese and Austrian cases confirm that the work they are doing in the regions centres around issues of novel local resource use, (neo)endogenous development, creating and supporting local supply chains and local networks and, therefore, promoting the development of the region alongside local development.

The implicit character of SI promotion may be related to several factors: (1) difficulties in identifying, defining and measuring SI and (2) some hesitation towards labelling the work as SI because of the 'buzz' around the term. It should be noted that, as evident from the interviews, there are some issues related to the fact that such organisations have to claim to be promoters of SI in order to access more funding opportunities. The impact assessment of SI projects puts further constraints on LAGs and LDAs because the organisations struggle with assessing, evaluating and/ or measuring the impacts produced.

Despite the role of SI in local development having been acknowledged in the literature (Moulaert et al. 2005; Neumeier 2012), future research on the role of LAGs and LDAs in promoting SI could benefit from a more critical perspective on SI as a political term used to fulfil the interests of some stakeholders. In addition, more attention could be paid to the contextual dimensions, political power structures at play, and potential undesired (or even negative) impacts of implementing such projects in rural regions.

Greater elaboration on the present research is needed about the interrelation of SI and social capital in rural regions and how the latter affects SI promotion. The research could also benefit from more insight into potential conflicts amongst various stakeholders in rural areas that lead to the disabling of social innovation.

\section{Acknowledgments}

This research has been carried out in the framework of the RurAction project that has received funding from the European Union's Horizon 2020 research and innovation programme under the Marie Sklodowska-Curie grant agreement No. 721999. The authors would like to thank the two anonymous reviewers for their helpful feedback and comments on this article. In addition, the authors would like to thank Sofia Bizzaro for her help with the figures presented in the article.

\section{References}

Angelidou M., Psaltoglou A., 2017. An empirical investigation of social innovation initiatives for sustainable urban development. Sustainable Cities and Society 33: 113-125.

Bock B.B., 2012. Social innovation and sustainability; how to disentangle the buzzword and its application in the field of agriculture and rural development. Studies in Agricultural Economics 114 (1316-2016-102759): 57-63.

Bock B.B., 2016. Rural marginalisation and the role of social innovation; a turn towards nexogenous development and rural reconnection. Sociologia Ruralis 56(4): 552-573. DOI: $10.1111 /$ soru.12119

Bosworth G., Rizzo F., Marquardt D., Strijker D., Haartsen T., Aagaard Thuesen A., 2016. Identifying social innovations in European local rural development initiatives. Innovation: The European Journal of Social Science Research 29(4): 442-461. 
Dax T., Fischer M., 2018. An alternative policy approach to rural development in regions facing population decline. European Planning Studies 26(2): 297-315.

Dax T., Strahl W., Kirwan J., Maye D., 2016. The LEADER programme 2007-2013: Enabling or disabling social innovation and neo-endogenous development? Insights from Austria and Ireland. European Urban and Regional Studies 23(1): 56-68. DOI: 10.1177/0969776413490425.

Di Iacovo F., Moruzzo R., Rossignoli C., Scarpellini P., 2014. Transition management and social innovation in rural areas: Lessons from social farming. The Journal of Agricultural Education and Extension 20(3): 327-347.

Dobele L., Grinberga-Zalite G., Kelle L., 2015. Sustainable economic development: Scenarios for promotion of social innovation in Latvia. Journal of Security \& Sustainability Issues 5(2): 149-158. DOI: 10.9770/jssi.2015.5.2(2).

Dargan L., Shucksmith M., 2008. LEADER and innovation. Sociologia ruralis 48(3): 274-291. DOI: 10.1111/j.14679523.2008.00463.x.

European Commission 2008. The EU Rural Development Policy: Facing the Challenges. Online: https://enrd. ec.europa.eu/enrd-static/fms/pdf/2067BB37-F930016B-4338-41FC992B5F58.pdf (accessed: 5 November 2019).

Eurostat 2016. Rural development statistics by urban-rural typology. Online: https://ec.europa.eu/eurostat/ statistics-explained/index.php?title=Archive:Rural_development_statistics_by_urban-rural_typology\&oldid=294503 (accessed: 15 November 2019).

Eurostat 2019. Database. Online: ec.europa.eu/eurostat/ data/database (accessed: 25 October 2019).

García-Llorente M., Rossignoli C., Di Iacovo F., Moruzzo R., 2016. Social farming in the promotion of social-ecological sustainability in rural and periurban areas. Sustainability 8(12): 1-15. DOI: 10.3390/su8121238.

Gobattoni F., Pelorosso R., Leone A., Ripa M.N., 2015. Sustainable rural development: The role of traditional activities in Central Italy. Land Use Policy 48: 412-427.

Hulgard L., Ferreira S., 2019. Social innovation and public policy. In: Howaldt J., Kaletka C., Schröder A., Zirngiebl M. (eds), Atlas of social innovation. 2nd volume - A world of new practices. oekom Verlag GmbH: Munich.

Margaras V., 2019. Demographic trends in EU regions. European Parliamentary Research Service. Online: http:/ / www.europarl.europa.eu/RegData/etudes / BRIE/2019/633160/EPRS_BRI(2019)633160_EN.pdf (accessed: 17 December 2019).

Marques P., Morgan K., Richardson R., 2018. Social innovation in question: The theoretical and practical implications of a contested concept. Environment and Planning C: Politics and Space 36(3): 496-512. DOI: 10.1177/2399654417717986.

Moulaert F., Sekia F., 2003. Territorial innovation models: A critical survey. Regional Studies 37(3): 289-302. DOI: 10.1080/0034340032000065442.

Moulaert F., Martinelli F., Swyngedouw E., Gonzalez S., 2005. Towards alternative model (s) of local in- novation. Urban Studies 42(11): 1969-1990. DOI: $10.1080=00420980500279893$

Moulaert F., 2010. Social innovation and community development: Concepts, theories and challenges. In: Moulaert F., Swyngedouw E., Martinelli F., Gonzalez S. (eds), Can neighbourhoods save the city? Routledge, Oxford: 20-32.

Navarro F., Labianca M., Cejudo E., de Rubertis S., Salento A., Maroto J.C., Belliggiano A., 2018. Interpretations of innovation in rural development. The cases of LEADER Projects in Lecce (Italy) and Granada (Spain) in 20072013 Period. European Countryside 10(1): 107-126. DOI: 10.2478/euco-2018-0007.

Neumeier S., 2012. Why do social innovations in rural development matter and should they be considered more seriously in rural development research? Proposal for a stronger focus on social innovations in rural development research. Sociologia Ruralis 52(1): 48-69. DOI: 10.1111/j.1467-9523.2011.00553.x.

Neumeier S., 2017. Social innovation in rural development: Identifying the key factors of success. The Geographical Journal 183(1): 34-46. DOI: 10.1111/geoj.12180.

Noack A., Federwisch T., 2019. Social innovation in rural regions: Urban impulses and cross-border constellations of actors. Sociologia Ruralis 59(1): 92-112. DOI: 10.1111/ soru.12216.

Phillips W., Lee H., Ghobadian A., O'Regan N., James P., 2015. Social innovation and social entrepreneurship: A systematic review. Group $\mathcal{E}$ Organization Management 40(3): 428-461. DOI: 10.1177/1059601114560063.

Pol E., Ville S., 2009. Social innovation: Buzz word or enduring term? The Journal of Socio-Economics 38(6): 878-885.

Ray C., 2006. Neo-endogenous rural development in the EU. In: Cloke P., Marsden T., Mooney P. (eds), Handbook of rural studies. SAGE Publications Ltd: 278-291.

Richter R., 2019. Rural social enterprises as embedded intermediaries: The innovative power of connecting rural communities with supra-regional networks. Journal of Rural Studies 70: 179-187.

Statistics Portugal 2019. Database. Online: https://www. ine.pt/xportal/xmain?xpid=INE\&xpgid=ine_main (accessed: 18 December 2019).

Strahl W., Dax T., 2010. Leader mainstreaming - new challenges to innovative local activities. Case study Austria, RuDI report, Work package 8. Vienna, Bundesanstalt fuer Bergbauernfragen: Wien, Austria.

Shucksmith M., Cameron S., Merridew T., Pichler F., 2009. Urban-rural differences in quality of life across the European Union. Regional Studies 43(10): 1275-1289.

Schumpeter J.A., 1911. The theory of economic development: An inquiry into profits, capital, credit, interest, and the business cycle, transaction books (1983). New Brunswick/New Jersey.

Tregear A., Cooper S., 2016. Embeddedness, social capital and learning in rural areas: The case of producer cooperatives. Journal of Rural Studies 44: 101-110. 